\section{Clinical consequences of poor adherence to lipid-lowering therapy in patients with cardiovascular disease: can we do better?}

\author{
Harry Klimis, ${ }^{1,2}$ Clara K Chow ${ }^{1,2}$
}

There is high-quality evidence demonstrating that early initiation of statin use following an acute coronary syndrome (ACS) and persistent use thereafter reduces the risk of major adverse cardiovascular events (MACE) including mortality. However, despite the overwhelming evidence, adherence remains suboptimal and the medications frequently discontinued. ${ }^{1}$ Here we discuss the data on lipid-lowering therapy among patients with cardiovascular disease and discuss some potential interventions that address the gap.

Among those with established atherosclerotic cardiovascular disease (ASCVD), poor statin adherence has been reported to be $47.2 \%$ in real-world registry data. $^{2}$ Discontinuation rates have been reported ranging from $14 \%{ }^{3}$ to $26.5 \%{ }^{4}$ at 12 months in both large multicentre randomised clinical trial (RCT) data and national registries, with long-term discontinuation being 51\% after 7 years in a large-scale RCT involving 39 countries. ${ }^{3}$ In a systematic review including 28 studies (5 nested case-control and 22 cohort studies), adherence to statin use in patients at high risk of ASCVD and those with established ASCVD was associated with a reduction in subsequent cardiovascular events (OR 1.22-5.26) and improved survival (OR 1.79-5.00). ${ }^{5}$ The US National Cardiovascular data Registry's PINNACLE database (data collected at the point of care at cardiology practices) was used in a large study that showed that in 1029633 adults with known ASCVD, 27.9\% did not receive any lipid-lowering medication. $^{6}$ Similarly, other registries demonstrate high proportions of patients not receiving lipid-lowering therapy within the first year following an ACS in Australia $^{7}$ and New Zealand ${ }^{8}-22 \%$ and $25 \%$ respectively.

${ }^{1}$ Department of Cardiology, Westmead Hospital, Sydney, New South Wales, Australia

${ }^{2}$ Westmead Applied Research Centre, University of

Sydney, Sydney, New South Wales, Australia

Correspondence to Prof Clara K Chow, Westmead Applied Research Centre, University of Sydney, Sydney, NSW, Australia; clara.chow@sydney.edu.au and Dr Harry Klimis; harry.klimis@sydney.edu.au syndrome.
Prescription of statins at the time of discharge after ACS is associated with continued use, ${ }^{7}$ and a range of data demonstrates significant gaps in use of lipid-lowering drugs among patients with cardiovascular disease. In the CONCORDANCE trial, failure to discharge patients on guideline-recommended therapies was 10 times more likely to result in non-adherence at 6 months post-ACS, indicating that initiation of lipid-lowering therapy during the index ACS hospitalisation is paramount in improving statin adherence. ${ }^{9}$ Yet, in some regions there is suboptimal use of lipid-lowering therapy at time of discharge from ACS. For example, national registry data from the USA found $39.3 \%$ of patients were not prescribed any lipid-lowering therapy during a hospital admission for ACS, although this reduced to $22.3 \%$ by 1 -year follow-up. ${ }^{4}$ This is different to registry data in New Zealand and Australia where $95 \%{ }^{8}$ and $92.7 \% 0^{7}$ of patients, respectively, post-ACS were prescribed statins on discharge.
Suboptimal persistence (continued use) of lipid-lowering therapy following an ACS event worsens over time (figure 1). In IMPROVE-IT (IMProved Reduction of Outcomes: Vytorin Efficacy International Trial), which involved 18144 patients with recent ACS across 39 countries, lipid-lowering therapy discontinuation rates were $6 \%$ at day $30,14 \%$ between 30 days and 1 year and $27 \%$ between 1 year and 7 years, and long-term persistence of statin use was poor with up to $51 \%$ discontinuing use after 7 years. ${ }^{3}$ Similarly in a New Zealand registry analysis of 1846 patients prescribed statins following discharge after ACS, ${ }^{8} 92 \%$ of patients had their statin dispensed at 3 months postdischarge, and this steadily decreased to $75.1 \%$ and $67.4 \%$ at 1 and 3 year timepoints, respectively.

In addition to poor adherence and persistence, there is suboptimal dosing of lipid-lowering therapy following ACS. In the PROVE IT-TIMI 22 (The Pravastatin or Atorvastatin Evaluation and Infection Therapy-Thrombolysis in Myocardial Infarction 22) trial $^{10}$ high-dose statin use following ACS reduced recurrent cardiovascular events and mortality compared with a lower dose statin regime. However, despite the research showing benefit, high-intensity statin is underused post-ACS. A recent Australian study using CONCORDANCE registry data (3441) demonstrated that up to 12 months following ACS, 55\% of patients

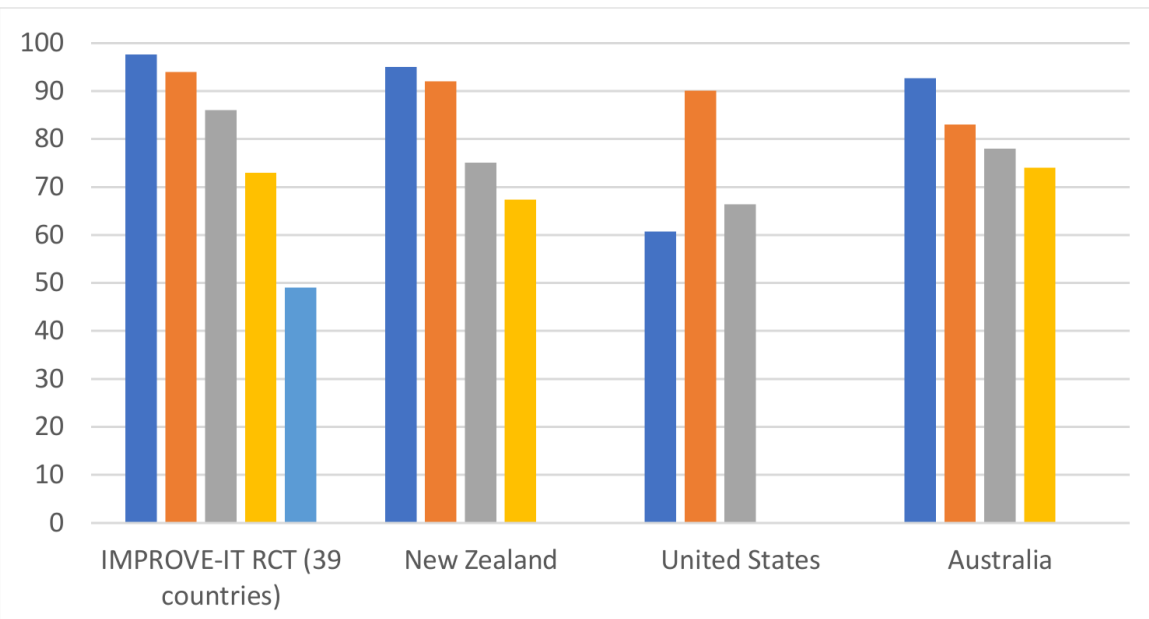

at discharge $\quad$ 1-6 months $\square$ 1-year $\square$ 1-7 years $\square 7$ years

Figure 1 Statin adherence and persistence from time of discharge post-ACS. Y axis represents \% taking statins. X-axis represents timepoint post-ACS. Data from IMPROVE-IT ${ }^{3}$ randomised clinical trial (RCT) and registries in New Zealand ${ }^{8}$ USA ${ }^{4}$ and Australia (CONCORDANCE). ${ }^{717}$ Maximum follow-up in USA was 1 year. One-year to 7-year data for New Zealand collected at 3 years and Australia collected at 2 years. Seven-year data only available for IMPROVE-IT. ACS, acute coronary 


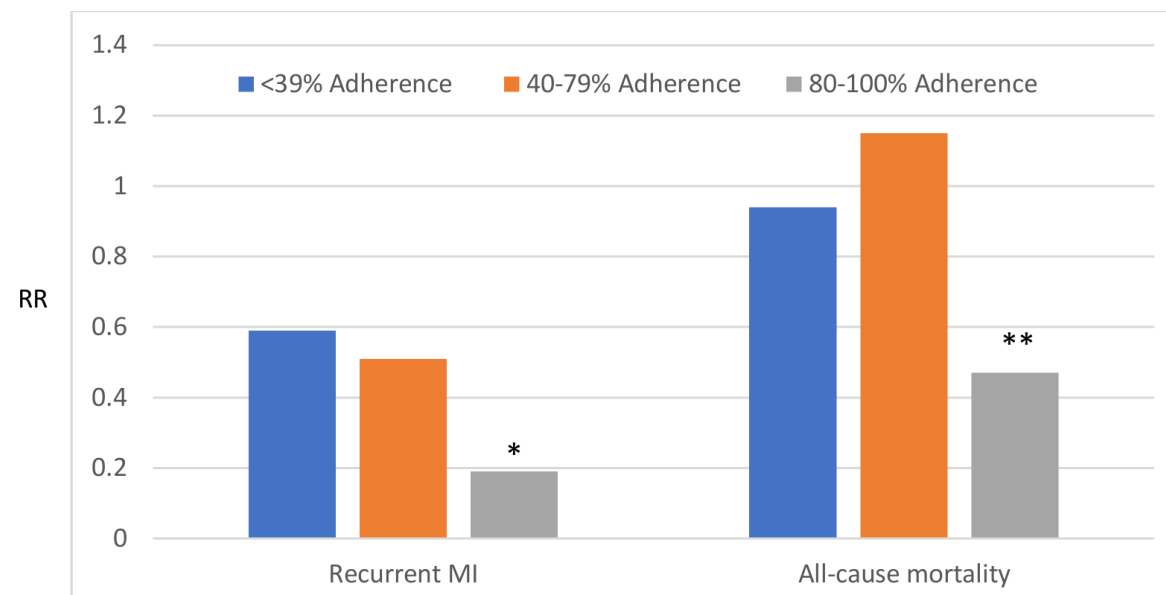

Figure 2 Effect of statin adherence on recurrent myocardial infarction (MI) and all-cause mortality in patients with established cardiovascular disease. ${ }^{1{ }^{*}} \mathrm{P}<0.01,{ }^{* *} \mathrm{p}<0.05$. RR, relative risk.

were receiving high-dose lipid-lowering therapy, 24\% were receiving some form of lipid-lowering therapy and 22\% were not receiving lipid-lowering therapy. ${ }^{7}$

Improved adherence to statins is associated with improved outcomes (Figure 2). A systematic review including 16 studies of people with established ASCVD, demonstrated that there is a reduction in all-cause mortality (OR $0.54,95 \%$ CI 0.50 to 0.59 ) and non-fatal cardiac events for high statin adherence (adherence levels of at least 80\%) and a reduction in all-cause mortality for statin persistence relative to the duration of statin use (adjusted OR (adjOR) 0.80 (95\% CI 0.66 to 0.97 ) for 1-12 month duration statin use compared with adjOR 0.20 (95\% CI 0.08 to 0.47 ) for $>60$ months' duration of statin use). ${ }^{11}$ Those that have statin intolerance are also probably doing worse. In a recent observational study published in JACC (Journal of the American College of Cardiology) assessing 105329 Medicare beneficiaries with recent myocardial infarction (MI), statin intolerance (defined as either down titrating simvastatin therapy and initiating ezetimibe or changing from simvastatin to ezetimibe) was associated with a $43 \%$ more coronary heart disease events (recurrent MI or coronary revascularisation) compared with those who had high statin adherence, but there was no significant change in all-cause mortality over a median follow-up period of 2 years. ${ }^{2}$

In this issue of BMJ Heart Asia, Shau and colleagues present new data uniquely from a large Asian population, demonstrating that statin adherence and persistence in patients with ASCVD is low and that this translates to higher risk of recurrent cardiac events and death in non-users of statins. This study analysed data from the Taiwan National Health Insurance (NHI) registry and involved over 185000 patients who were initiated on statin therapy for a new diagnosis of ASCVD. Only 53\% of patients had optimal statin adherence by the end of the follow-up period (mean 2.2 years; range 1-7 years). Only 50\% had 'constant use' of statins (baseline state which changed depending on use patterns) for the duration of the study, with 26\% 'non-persistent' (defined as more than 90-day gap after end of the latest prescription), $13 \%$ that recently stopped (defined as less than 90-day gap after end of the latest prescription) and $11 \%$ intermittently taking statins (if restarted statins after the 'non-persistent' state). Shau and colleagues found that good adherence to statin therapy was associated with significantly less ASCVD-related hospital readmissions: composite MACE (defined as MI, ischaemic stroke and stable CHD (coronary heart disease) requiring revascularisation), recurrent MI and ischaemic strokes compared with poor adherence. Furthermore, good adherence was associated with significantly less fatal ASCVD events including in-hospital death for recurrent MI and ischaemic stroke. Persistent statin use defined as 'constant use', that is, no more than 90-day disruption in statin use, was associated with significantly lower risk of recurrent ASCVD-related hospital readmissions-recurrent $\mathrm{MI}$ and ischaemic stroke. Additionally, those who failed to fill their statin prescription (i.e. had more than a 90-day disruption) had a significantly higher risk of in-hospital fatal outcomes (fatal MI and ischaemic stroke) compared with those who did refill their prescription .

The results are overall consistent with results in similar studies outside of Asia; however, some limitations are notable. First, statin use was indirectly assumed via prescription records; that is, actual consumption was not recorded. The data were captured through an electronic national database-The Taiwan NHI compulsory programme implemented in 1995. The authors state that in 2014, over $99 \%$ of the Taiwan population was enrolled and thus the risk of uncaptured data is low, although this was not addressed in the paper, and it is unclear if this database links non-hospital data that is, it may have been possible to miss cardiac events including deaths occurring outside of hospital. Additionally, reasons for statin non-adherence were not captured, and further research in this area would help to address the gap. Previous studies have demonstrated improved outcomes with high-dose statins vs lower dose regimes, and it would have been of interest if dosage could have been examined, as there has been some indication of lower doses of statins used in some Asian countries compared with non-Asian countries. ${ }^{12}$

High intensity lipid-lowering medications are recommended by current treatment guidelines for patients post-ACS. Despite this, registries across the world reveal substantial underutilisation, poor adherence and lack of persistent use in secondary prevention settings. Some studies have explored the reasons for poor adherence, which include adverse effects, non-obstructive coronary artery disease, patient misunderstanding, advice from treating doctor and access barriers. ${ }^{13}$ We need to explore whether there are cultural and regional variation in these barriers to inform and develop interventions to address adherence and persistence to important secondary prevention medications such as lipid-lowering drugs. There are some interventions that have been shown to improve adherence and persistence to statins and other secondary prevention medications including fixed-dose combination pills (polypill), ${ }^{14}$ patient education with behavioural support and policies reducing out-of-pocket expenses. ${ }^{15}$ Some recent studies have also explored the role of mobile health technology in 
addressing adherence. ${ }^{16}$ Greater awareness of this issue is also likely to help, and perhaps one easy target is to at least ensure the initiation of these medications for all patients with ACS during their index hospitalisation.

Funding The authors have not declared a specific grant for this research from any funding agency in the public, commercial or not-for-profit sectors.

Competing interests None declared.

Patient consent for publication Not required.

Provenance and peer review Commissioned; internally peer reviewed.

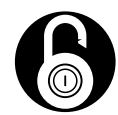

\section{OPEN ACCESS}

Open access This is an open access article distributed in accordance with the Creative Commons Attribution Non Commercial (CC BY-NC 4.0) license, which permits others to distribute, remix, adapt, build upon this work non-commercially, and license their derivative works on different terms, provided the original work is properly cited, appropriate credit is given, any changes made indicated, and the use is non-commercial. See: http://creativecommons.org/ licenses/by-nc/4.0/.

(c) Author(s) (or their employer(s)) 2019. Re-use permitted under CC BY-NC. No commercial re-use. See rights and permissions. Published by BMJ.

\section{D) Check for updates}

To cite Klimis $\mathrm{H}$, Chow CK. Heart Asia 2019;11:e011200. doi:10.1136/ heartasia-2019-011200

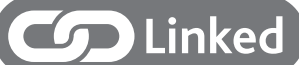

- http://dx.doi.org/10.1136/heartasia-2018-011176

Heart Asia 2019;11:e011200. doi:10.1136/

heartasia-2019-011200

\section{REFERENCES}

1. Rosenson RS, Farkouh ME, Mefford M, et al. Trends in Use of High-Intensity Statin Therapy After Myocardial Infarction, 2011 to 2014. J Am Coll Cardiol 2017;69:2696-706.

2. Serban M-C, Colantonio LD, Manthripragada AD, et al. Statin intolerance and risk of coronary heart events and all-cause mortality following myocardial infarction. J Am Coll Cardiol 2017;69:1386-95.

3. Navar AM, Roe MT, White JA, et al. Medication discontinuation in the IMPROVE-IT trial. Circ Cardiovasc Qual Outcomes 2019;12:e005041.

4. Boklage SH, Malangone-Monaco E, Lopez-Gonzalez $L$, et al. Statin utilization patterns and outcomes for patients with acute coronary syndrome during and following inpatient admissions. Cardiovasc Drugs Ther 2018;32:273-80.

5. De Vera MA, Bhole V, Burns LC, et al. Impact of statin adherence on cardiovascular disease and mortality outcomes: a systematic review. Br J Clin Pharmacol 2014;78:684-98.

6. Maddox TM, Borden WB, Tang F, et al. Implications of the 2013 ACC/AHA cholesterol guidelines for adults in contemporary cardiovascular practice: insights from the NCDR pinnacle registry. J Am Coll Cardiol 2014:64:2183-92.

7. Brieger D, D'Souza M, Hyun K, et al. Intensive lipidlowering therapy in the 12 months after an acute coronary syndrome in Australia: an observational analysis. Med J Aust 2019;210:80-5.

8. Kerr AJ, Turaga M, Grey C, et al. Initiation and maintenance of statins and aspirin after acute coronary syndromes (ANZACS-QI 11). J Prim Health Care 2016:8:238-49.
9. Brieger D, Chow C, Gullick J, et al. Improving patient adherence to secondary prevention medications 6 months after an acute coronary syndrome: observational cohort study. Intern Med J 2018:48:541-9.

10. Cannon CP, Braunwald E, McCabe $\mathrm{CH}$, et al. Intensive versus moderate lipid lowering with statins after acute coronary syndromes. $N$ Eng/ I Med 2004;350:1495-504.

11. Simpson RJ, Mendys P. The effects of adherence and persistence on clinical outcomes in patients treated with statins: a systematic review. J Clin Lipidol 2010;4:462-71.

12. Li DQ, Kim RB, McArthur E, et al. Statin safety in Chinese: a population-based study of older adults. PLoS One 2016;11:e0150990.

13. Yu G, Zhang Y, Wang Y, et al. Factors that contribute to poor adherence to statin therapy in coronary heart disease patients from Chongqing and measures to improve their therapeutic outcomes. Genes Dis 2018;5:335-41.

14. Bartlett LE, Pratt N, Roughead EE. Does a Fixed-dose combination of amlodipine and atorvastatin improve persistence with therapy in the Australian population? Curr Med Res Opin 2018;34:305-11.

15. Viswanathan $\mathrm{M}$, Golin $C E$, Jones $C D$, et al. Interventions to improve adherence to selfadministered medications for chronic diseases in the United States: a systematic review. Ann Intern Med 2012;157:785-95.

16. Thakkar J, Kurup R, Laba T-L, et al. Mobile telephone text messaging for medication adherence in chronic disease: a meta-analysis. JAMA Intern Med 2016;176:340-9.

17. Chow CK, Brieger D, Ryan M, et al. Secondary prevention therapies in acute coronary syndrome and relation to outcomes: observational study. Heart Asia 2019:11:e011122.

18. Wei L, Wang J, Thompson P, et al. Adherence to statin treatment and readmission of patients after myocardial infarction: a six year follow up study. Heart 2002;88:229-33. 